REVISTA DE DERECHO UNED, NÚM. 27, 2021

\title{
BUQUERAS Y BACH, IGNACIO. CAMBÓ. EDITORIAL ALMUZARA. CÓRDOBA, 2019. 504 PÁGS.
}

\author{
BUQUERAS Y BACH, IGNACIO. CAMBÓ. EDITORIAL ALMUZARA. \\ CÓRDOBA, 2019. 504 PAGES.
}

Federico Fernández De Buján

Catedrático de Derecho Romano. UNED

Ignacio Buqueras es uno de esos personajes del mundo cultural que pueden definirse como "una fuerza desatada de la naturaleza". Su capacidad de trabajo asombra al más esforzado. Sus "frentes" son tan ricos como intensos. Economista y Doctor en Ciencias de la Información. Académico de la Real Academia de Doctores de España, de la Real Academia del Mar y de la Real Academia Europea de Doctores. Presidente y Consejero de varias sociedades, entre ellas dedica especial atención a Comisión Nacional para la Racionalización de los Horarios. Autor de numerosos libros especialmente dedicados a la sociedad civil, la educación y a los horarios. Así, entre otros: Cataluña en Madrid, 1984; Josep Pla, el "seny" irónico, 1985; Redescubrir América. Descubrir España, 1985; Objetivo 92: España en el Mundo, 1988; Más Sociedad, menos y mejor Estado, 2002; Tiempo al Tiempo, 2006.

Es un prototipo de intelectual creativo. Tiene talento innato, que ha hecho fructificar; vocación intelectual, traducida en su pasión por descubrir; vitalidad, que le posibilitan mantener una disciplina rigurosa; espíritu insatisfecho, que le hace cuestionar los resultados del saber; iniciativa alerta, que le lleva a pisar senderos no explorados; y sentido social que le mueve a proponer reformas y propugnar conquistas para alcanzar el interés general y el bien común. 
Treinta y un años después de la publicación de su ensayo "Cambó" y en una grave y preocupante situación política y social con la que España vive la cuestión catalana, Buqueras se anima a rescribir aquel magnífico ensayo y a enriquecerlo con nuevas reflexiones que lo acercan a la problemática actual. Y lo hace con el acierto de quien como catalán encuentra en el conjunto de España su ámbito y proyección de orden natural.

El libro aproxima al lector a las distintas etapas de la vida y obra de Cambó enmarcadas en sus contextos histórico, geográfico, socioeconómico, constitucional y de actividad pública. Destaca el A. -de entre las entrevistas y la correspondencia que aporta del biografiado-, la amable conversación que tuvo con su hija Helena Cambó, con la departió largamente. A ello, suma un rico mosaico de interesantes testimonios. Las referencias de ilustres personalidades al político biografiado que contenía la primera edición, así, Marañón, Madariaga, Tarradellas, Ruiz Giménez, Fraga, Ferrer Salat, entre otros, se ven enriquecidas, notablemente, en la nueva edición con las aportaciones de Antonio Garrigues, el Arzobispo de Tarragona, Guardans Cambó, el Abad de Poblet, Josep Rosiñol, Pere Huguet, Jordi Jané, Ramón Tamames. Así, el "nuevo Cambó" de Buqueras logra una aproximación de su pensamiento y actuación política que se convierte en apta para contrastarlas con el momento actual y convertirse en un valioso testimonio -digno de ser tenido en consideración- en la valoración de los hechos que son hoy objeto de análisis y preocupación.

Buqueras nos descubre en Cambó: "su excepcional preparación, dotes oratorias, poder de convicción, vocación humanista, férrea voluntad, espiritu moderado, en suma, su dualidad como hombre de acción y pensamiento". El A. tiene la capacidad narrativa de describir como Cambó ha sido un político renovador que a nadie dejo indiferente. Así, nos relata que fue un catalanista que nunca consideró contrapuestas las ideas de Cataluña y España, por lo que junto a numerosos y fervientes partidarios, no faltaron aquellos quienes clamaban: "Muera Cambó".

Son muy interesantes los capítulos dedicados a su pensamiento, vivencias, actividades y mecenazgo. Este último constituye una faceta poco conocida. Buqueras la considera esencial en la historia del Museo del Prado. No está de más recordarlo para agradecerlo, en este año que celebramos el 200 Aniversario de la Institución. Descubre el A. que las negociaciones y el coste económico para el traslado de las obras del Museo del Prado a Montreux (Suiza), durante la guerra civil, corrieron a cargo de Cambó. 
El legado de Cambó a Barcelona es excepcional. Son unas cincuenta obras desde el Trecento italiano hasta Goya que pueden admirarse en el Museo Nacional d'Art de Cataluya. Su mecenazgo abarcó también a las Fundaciones Bernat Metge, Biblia Catalana, y a las colecciones Classics de tots els Temps y Monumenta Cataloniae.

Si el primer ensayo de Buqueras vio la luz en el cuarenta aniversario del fallecimiento de Cambó en Buenos Aires, esta nueva edición puede contribuir con su lectura a encontrar un referente político para muchos jóvenes que, tal vez, no conozcan la trayectoria vital del personaje. Consciente de ello, en su primera página, el A. estampa esta preciosa y sentida dedicatoria: "A cuántos desde su 'ser' catalán trabajan con ilusión, inteligencia, y tenacidad por una mejor España de todos".

Ignacio Buqueras se siente reconfortado con el mensaje que el Rey Felipe VI dirigió, recientemente, a los catalanes cuando les dijo: "No estáis solos". En ese espíritu, considera que haría mucho bien la abundancia de mensajes de amistad y apoyo a amigos y conocidos catalanes, tanto desde los ámbitos privados como en la esfera pública.

Aporto alguno de los luminosos pensamientos de Cambó que se recogen en el ensayo:

- Sobre el idioma: "No se le quite al niño la lengua que le es propia, porque ello es quitarle el carácter" (1913).

- Sobre el separatismo: "El separatismo en los pueblos es como el suicidio en los individuos: es un acto de desesperación, casi de irresponsabilidad. Se puede ser separatista, como se puede ser suicida, en un momento de pesimismo, de debilidad, de agotamiento. Pero ¿cómo puede conducir al separatismo un movimiento que es todo lo contrario, que es todo fe, que es todo optimismo, que es todo esperanza?" (1907).

- Sobre España: "Creo en Cataluña porque creo en España ¿Hay alguien que pueda pensar por un momento que la grandeza de Cataluña pueda chocar, lastimar en algo el progreso y la vida y la dignidad de España? (1907).

- Sobre las autonomías. "Cuanto más fuertes sean las regiones, más fuerte será España". "Decid a las demás regiones que no les tenemos odio, que nuestro odio va dirigido a todo lo que nos separa de ellas..." (1914). 
El libro se enriquece con un "prólogo" de quien fue presidente del Consejo General de la Abogacía, Senador real y Consejero de Estado, Antonio Pedrol Rius y un "epílogo" del maestro de periodistas Emilio Romero. Finaliza con un exhaustivo capítulo bibliográfico y un completo índice onomástico.

En suma, el Cambó de Buqueras arroja un haz de luz para aproximarse a una importante personalidad del pasado siglo español, no solo como político, sino también como empresario y mecenas de la cultura.

Describe Ortega y Gasset como algunos “...conservan hasta la senectud un poder de plasticidad inexhausto, una juventud perdurable que les permite renacer y reformarse dos y aún tres veces durante la vida". Ciertamente, Ignacio Buqueras -que por su edad se encuentra en la plenitud de la senectud- responde a este biotipo. 